\title{
GLUCOCORTICOIDS STIMULATE ADRENERGIC DIFFERENTIATION IN CULTURES OF MIGRATING AND PREMIGRATORY NEURAL CREST $^{1}$
}

\author{
J. SMITH ${ }^{2}$ AND M. FAUQUET \\ Institut d'Embryologie du Centre National de la Recherche Scientifique et du Collège de France, 94130 Nogent sur Marne, France
}

January 6, 1984; Accepted February 27, 1984

\begin{abstract}
Glucocorticoid hormones stimulate catecholamine (CA) anabolism in a variety of adrenergic derivatives of the neural crest. We describe work performed to investigate the action of these steroids on the catecholaminergic differentiation of neural crest cells themselves.

Crest was taken from the trunk level of 2-day quail embryos, before migration had begun, and was cultured in vitro. Adrenergic differentiation, characterized by the ability of the cultures to synthesize and store CA, was minimal and was not improved when glucocorticoids were added to the medium. In contrast, extensive adrenergic differentiation occurred when neural crest cells, removed from the embryo 24 hr later, toward the end of their migratory phase, were cultured with the sclerotomal component of the somite (their immediate embryonic microenvironment). This process was considerably stimulated by corticosteroids; the rate of conversion of $\left[{ }^{3} \mathrm{H}\right]$ tyrosine to intracellular $\mathrm{CA}$ (norepinephrine, epinephrine, and dopamine) was 2 to 3 times higher in cultures exposed for 7 days to $10^{-6}$ to $10^{-7} \mathrm{M}$ hydrocortisone, corticosterone, or dexamethasone, and the diameter of the dense-core vesicles seen in cell bodies and processes after permanganate fixation was strikingly increased. The effect was specific for the adrenergic phenotype in that acetylcholine synthesis by the cultures was consistently unaffected by hormone treatment.

We infer that glucocorticoids do not trigger adrenergic differentiation, but that they selectively enhance catecholaminergic properties in crest cells that have already been exposed to an appropriate signal of another kind. This conclusion is strengthened by the observation that glucocorticoids stimulated the development of CA-producing cells from premigratory crest grown in the presence of somites and notochord, postulated sources of factors initiating adrenergic differentiation in the embryo.

Although the intervention of glucocorticoids in vivo at very early embryonic stages remains to be established, our results indicate that neural crest derivatives would be potentially responsive to these hormones as soon as the sympathetic ganglia form.
\end{abstract}

The early phases of peripheral neurogenesis - the transformation of neural crest into phenotypically distinct ganglion cells-are coming under increasing scrutiny on the part of developmental neurobiologists. One of the major problems centers upon the mechanisms whereby relatively undifferentiated and apparently identical embryonic cells give rise to the broad spectrum of structurally and biochemically specialized elements that characterize the sensory and autonomic nervous systems.

Evidence has recently been obtained that a number of committed precursors of peripheral neurons exist in the neural crest before migration is under way (Ziller et al., 1983). On the other hand, it has been clearly demonstrated that factors ex-

${ }^{1}$ This work, carried out with the technical assistance of C. Breant, G. Gateau, and B. Louis, was supported by the Centre National de la Recherche Scientifique, the Délégation Générale à la Recherche Scientifique et Technique, and by Grant 1 RO1 DE 04257-01 CBY from the National Institutes of Health. We wish to thank Prof. N. M. Le Douarin for helpful advice and discussion.

${ }^{2}$ To whom correspondence should be addressed. trinsic to the neural crest play a crucial role in the development of certain key neuronal properties. In particular, external influences are strongly implicated in the processes leading to the establishment of chemical diversity within the developing nerve cell population (for reviews, see Patterson, 1978; Le Douarin et al., 1981; Le Douarin, 1982). A case in point is the acquisition of the noradrenergic phenotype; the combined results of a number of experimental studies on embryonic avian tissues in vivo and in organ culture have led to the conclusion that catecholaminergic differentiation is elicited by signals emanating from tissues (somites, notochord, ventral neural tube) bordering or close to the migration pathways followed by the cervicothoracic crest cell precursors of the sympathetic ganglionic chain (Cohen, 1972; Norr, 1973, Teillet et al., 1978).

An in vitro approach should facilitate access to the interactive mechanisms governing the development of adrenergic cells. In a previous publication, we reported that neural crest, taken from a 2-day embryo before the onset of the migration process and cultured alone in a medium supplemented with $15 \%$ serum and $2 \%$ chick embryo extract, produced barely discernible 
amounts of catecholamine (CA). On the other hand, rapid and extensive differentiation of cells possessing properties of authentic sympathetic neurons (judging by ultrastructural, cytological, and biochemical criteria) occurred when "migrating" neural crest and sclerotomal mesenchyme, taken together from the trunk of 3-day quail embryos, were cultured in the same medium (Fauquet et al., 1981). In the course of our subsequent attempts to obtain adrenergic differentiation from premigratory crest cells, we were led to study the effects of glucocorticoid hormones on the acquisition and development of catecholaminergic properties in neural crest in vitro.

Our investigation of the action of glucocorticoids was prompted by previous well documented observations that they can increase the content of CA and the activity of CA-synthes izing enzymes in neural crest derivatives in vivo and in vitro (Eränkö et al., 1973; Costa et al., 1974; Hervonen and Eränkö, 1975; Otten and Thoenen, 1976a; Sandquist et al., 1979; Bohn et al., 1981). In studies perhaps even more relevant to the initial stages of autonomic neuron development and the selection of transmitter-related phenotype, they had also been shown to stimulate preferentially the expression of catecholaminergic properties in cell populations that display both adrenergic and cholinergic features (Fukada, 1980; McLennan et al., 1980; Schubert et al., 1980). Therefore, it appeared opportune to examine the effects of glucocorticoids on the conversion of neural crest cells to adrenergic neurons in vitro. Demonstration of hormonal action during this extremely early phase of neurogenesis could have interesting implications for neural development in the young embryo.

In the experiments detailed here, we have examined the effects of glucocorticoid hormones on adrenergic differentiation in cultures of migrating and premigratory trunk neural crest. Since such cultures also express certain properties characteristic of cholinergic neurons (i.e., choline acetyltransferase and acetylcholinesterase activities), we were able, by simultaneous evaluation of adrenergic and cholinergic development in the presence and absence of exogenous glucocorticoids, to assess the phenotypic specificity of response to hormone. The results show that, in the presence of tissue of noncrest origin, adrenergic differentiation of both types of neural crest can be stimu-

\section{'AABLE I}

Effect of corticosterone on CA synthesis in trunk neural crest cultured alone

The conversion of $\left[{ }^{3} \mathrm{H}\right]$ tyrosine to $\mathrm{CA}$ was measured in cultures of premigratory trunk neural crest grown for 7 days in the presence and absence of exogenous corticosterone.

\begin{tabular}{lc}
\hline & CA Synthesized \\
\hline & fmol/dish \\
Control $(n=5)$ & $3.0 \pm 1.8$ \\
$+10^{-6}$ M Corticosterone $(n=6)$ & $3.7 \pm 3.7$ \\
\hline
\end{tabular}

\section{TABLE II}

Effect of hydrocortisone on neurotransmitter synthesis in cultured neural crest/sclerotome

The conversion of $\left[{ }^{3} \mathrm{H}\right]$ tyrosine and $\left[{ }^{3} \mathrm{H}\right]$ choline to $\mathrm{CA}$ and $\mathrm{ACh}$ was determined in cultures of migrating trunk neural crest together with sclerotomal mesenchyme, grown for 7 days in the presence or absence of exogenous hydrocortisone.

\begin{tabular}{lcc}
\hline & \multicolumn{2}{c}{$\begin{array}{c}\text { Neurotransmitter } \\
\text { Synthesized }\end{array}$} \\
\cline { 2 - 3 } & CA $\quad$ fmol/dish \\
\hline Control $(n=6)$ & \multicolumn{2}{c}{ ACh } \\
$+10^{-6}$ M Hydrocortisone $(n=8)$ & $1054 \pm 211^{a}$ & $339 \pm 22$ \\
\hline
\end{tabular}

${ }^{a}$ Differs significantly from the control $(p<0.02)$.

\section{TABLE III}

Effect of hydrocortisone and corticosterone on the synthesis of different CAs in cultured neural crest/sclerotome

The quantity of NE and DA synthesized from $\left[{ }^{3} \mathrm{H}\right]$ tyrosine during a 4-hr incubation was determined, by HPLC analysis, in cultures grown in the presence and absence of added glucocorticoid.

\begin{tabular}{|c|c|c|}
\hline & \multicolumn{2}{|c|}{$\begin{array}{l}\text { Catecholamine } \\
\text { Synthesized }\end{array}$} \\
\hline & $\mathrm{NE}$ & DA \\
\hline & \multicolumn{2}{|c|}{$\mathrm{fmol} / \mathrm{dish}$} \\
\hline $\begin{array}{l}\text { Control }(n=8) \\
+10^{-6} \text { M Hydrocortisone }(n=8)\end{array}$ & $\begin{aligned} 782 & \pm 93 \\
1474 & \pm 206^{a}\end{aligned}$ & $\begin{array}{c}52 \pm 18 \\
321 \pm 75^{b}\end{array}$ \\
\hline $\begin{array}{l}\text { Control }(n=10) \\
+10^{-6} \text { M Corticosterone }(n=5)\end{array}$ & $\begin{array}{c}919 \pm 154 \\
2327 \pm 456^{a}\end{array}$ & $\begin{array}{c}38 \pm 5 \\
366 \pm 89^{b}\end{array}$ \\
\hline
\end{tabular}

${ }^{a}$ Differs significantly from the control $(p<0.01)$.

${ }^{b}$ Differs significantly from the control $(p<0.005)$.

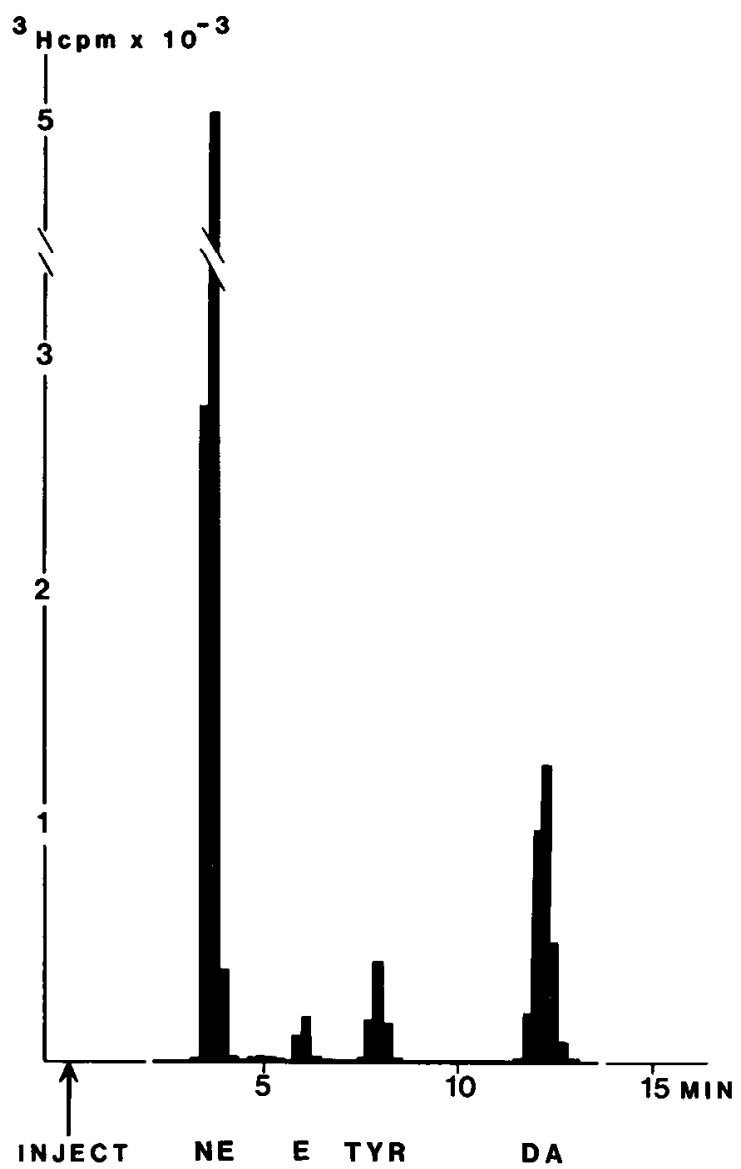

Figure 1. HPLC elution profile of CA synthesized by neural crest/ sclerotome cultures after hydrocortisone treatment. Twenty neural crest/sclerotome explants were grown for 7 days in medium supplemented with $10^{-6} \mathrm{M}$ hydrocortisone. After incubation with $\left[{ }^{3} \mathrm{H}\right]$ tyrosine, the radioactive CA produced were analyzed by HPLC as described under "Materials and Methods." The distribution of radioactivity eluted from the column is shown together with the positions of marker amines.

lated by glucocorticoids. In contrast, no hormonal effect on acetylcholine $(\mathrm{ACh})$ synthesis was observed under any of the culture conditions studied.

\section{Materials and Methods}

Isolation of embryonic rudiments. Japanese quail embryos, incubated at $38^{\circ} \mathrm{C}$, were the source of all tissues. 


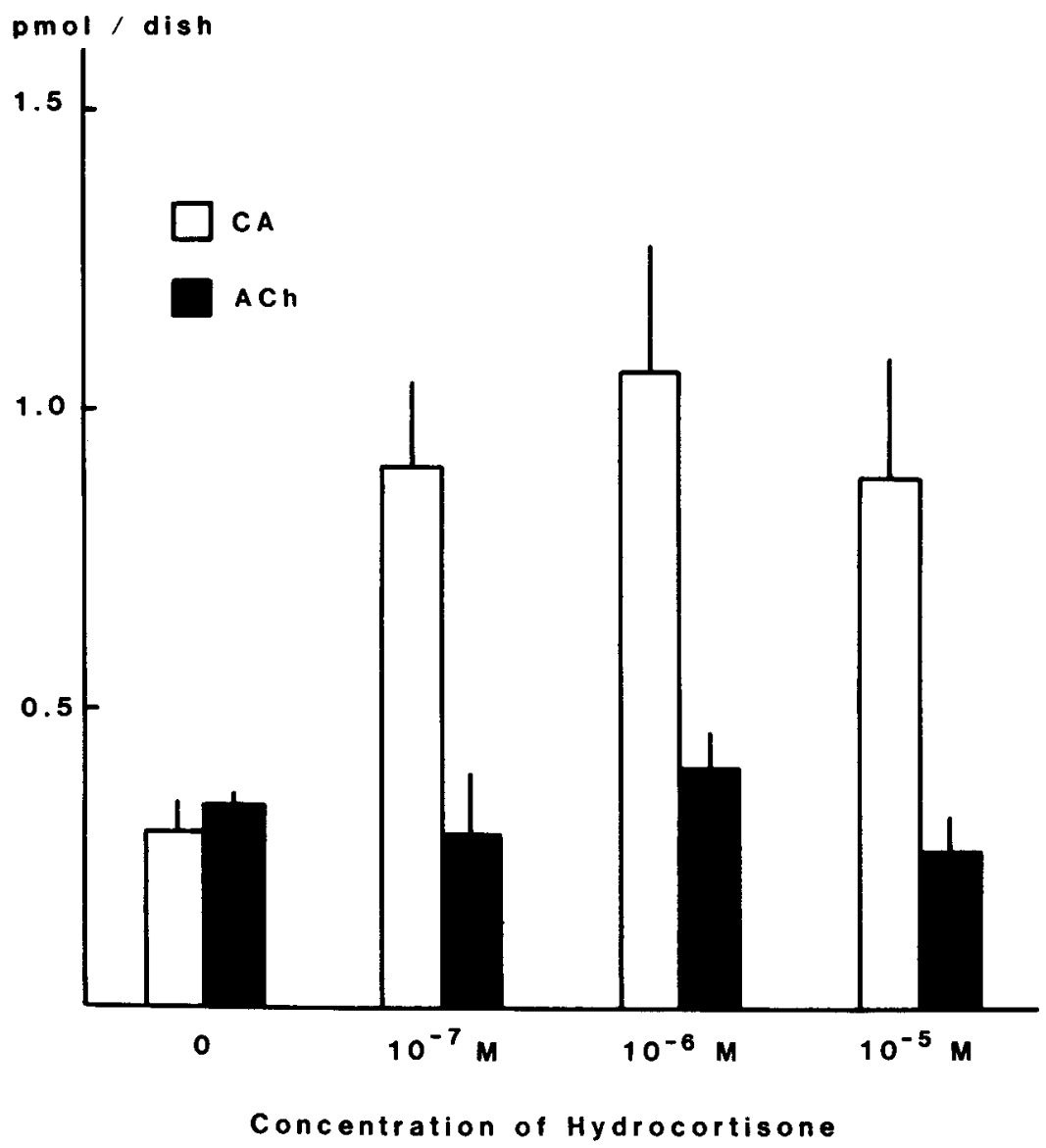

Figure 2. Effect of hydrocortisone on neurotransmitter synthesis and accumulation in cultured neural crest/sclerotome. Cultures were grown for 7 days in media containing the indicated concentrations of hydrocortisone. The conversion of $\left[{ }^{3} \mathrm{H}\right]$ tyrosine and $\left[{ }^{3} \mathrm{H}\right]$ choline to $\mathrm{CA}(\mathrm{NE}, \mathrm{E}$, and $\mathrm{DA})$ and $\mathrm{ACh}$ was determined in each as described under "Materials and Methods." The results, expressed as picomoles synthesized per $4 \mathrm{hr}$ per dish, are means \pm SEM of valucs obtained for three to eight cultures assayed at each concentration of the glucocorticoid. The quantity of CA produced by all hydrocortisone-treated cultures differs significantly from the control $(p<0.02)$.

Premigratory trunk neural crest was excised surgically from the tips of the neural folds in embryos of 12 to 16 pairs of somites. Unsegmented somitic mesenchyme (of a length equivalent to three to four somites) and notochord were isolated from 2-day embryos (14 to 18 pairs of somites) and sclerotomes, intimately associated with migrating trunk neural crest, were obtained from 3-day embryos as described previously (Fauquet et al., 1981).

Culture methods. Cultures that were to be examined biochemically were grown in Falcon Multiwell dishes (16-mm diameter), each well containing 14 neural crest explants or 20 sclerotomes, placed without previous dissociation directly on the plastic surface. When neural crest was co-cultured with somitic mesenchyme and notochord, explants of the non-neural tissues (four explants/well) were grown for 3 to 4 days before addition of the crest fragments. Cultures that were to be treated to reveal CA histofluorescence were grown on glass coverslips coated with calf-skin collagen.

The culture medium was Dulbecco's modified minimum essential medium (Gibco) supplemented with $15 \%$ heat-inactivated fetal calf serum (Gibco) and $2 \%$ 9-day chick embryo extract. For some experiments, endogenous steroids were removed from the serum and embryo extract by charcoal extraction (Armelin et al., 1974). Corticosterone, hydrocortisone, progesterone, and cortexolone (11-deoxy-17-hydroxycorticosterone acetate) were obtained from Sigma. Estradiol benzoate and testosterone propionate were purchased from l'Industrie Biologique Française. The steroids were dissolved in alcohol and added to the medium shortly after attachment of the neural crest or sclerotome explants. Control cultures were given an equivalent volume of alcohol (final concentration $0.5 \%$ ). All cultures were grown at $37^{\circ} \mathrm{C}$ in air: $\mathrm{CO}_{2}$
(95:5). Unless otherwise stated, neural crest and sclerotome cultures were examined biochemically or cytochemically 7 days after explantation; co-cultures of neural crest with somite and notochord were treated 7 days after addition of the neural crest. The culture medium was not changed during this period.

CA cytochemistry. CA stores were visualized in cultures by glyoxylic acid-induced fluorescence according to the method of König (1979).

Electron microscopy. Cultures were fixed in potassium permanganate according to the technique of Ross et al. (1977), stained with uranyl acetate, embedded in Epon, and observed using a Hitachi HS 9 microscope.

Determination of neurotransmitter synthesis and accumulation. Synthesis of $\mathrm{CA}$ and $\mathrm{ACh}$ was measured after incubating cultures for $4 \mathrm{hr}$ with L-[side chain $\left.-2,3-{ }^{3} \mathrm{H}\right]$ tyrosine and $\left[\right.$ methyl $\left.-{ }^{3} \mathrm{H}\right]$ choline (Amersham), followed by high voltage paper electrophoresis, as described earlier (Fauquet et al., 1981). In some experimental series, CAs were separated by high performance liquid chromatography (HPLC), which, unlike electrophoresis, enables norepinephrine (NE) to be distinguished from epinephrine (E). For these experiments, $\left[{ }^{3} \mathrm{H}\right]$ choline was omitted from the incubation medium and replaced by $50 \mu \mathrm{M}$ unlabeled choline. At the end of the incorporation period, the cells were rinsed, collected, and disrupted by ultrasonication in buffer $(0.4 \mathrm{M}$ acetic acid/0.1 $\mathrm{M}$ formic acid, $\mathrm{pH}$ 2) containing unlabeled CA markers. After deproteinization with $0.5 \mathrm{~N}$ perchloric acid, the samples were analyzed by reversed-phase HPLC, using a model 6000 solvent delivery system, a model U6K sample injector, a model 440 absorbance detector, and a 30-cm $\mu$ Bondapak $\mathrm{C}_{18}$ reversed-phase column (all from Waters Associates). Amines were separated by isocratic elution with a mobile phase 


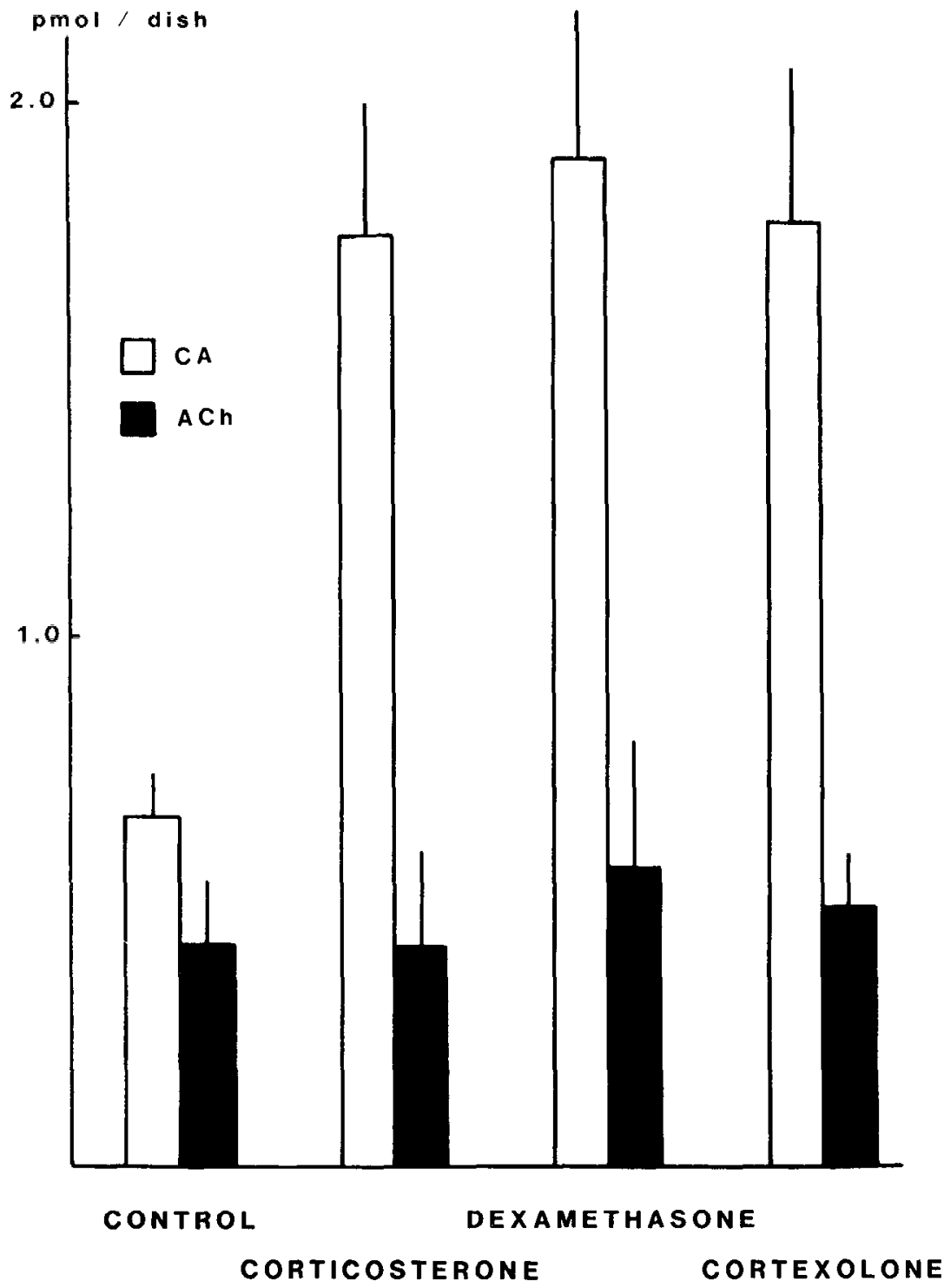

Figure 3. Effect of various corticosteroids on neurotransmitter synthesis and accumulation in cultured neural crest/sclerotome. Cultures were grown in the presence of the indicated steroids at $10^{-6} \mathrm{M}$, or in the absence of exogenous hormone (control). Synthesis and accumulation of $\mathrm{CA}$ and $\mathrm{ACh}$ were measured after 7 days. The quantities of neurotransmitter produced are the means \pm SEM of determinations carried out on 4 to 10 cultures in each medium. 'The values for CA produced by all corticosteroidtreated cultures differ significantly from the control $(p<0.005)$.

similar to that described by Asmus and Freed (1979), composed of 0.1 $\mathrm{M}$ trichloroacetic acid in $5 \%$ methanol, adjusted to $\mathrm{pH} 3.05$ with $\mathrm{NaOH}$ just before use. Fractions of $500 \mu$ l were collected, and their radioactivity was determined by scintillation spectrometry. The positions of the marker substances were determined by their absorbance at $280 \mathrm{~nm}$.

Neurotransmitter synthesis and accumulation were calculated as femtomoles or picomoles per culture per $4 \mathrm{hr}$, and the numerical data were analyzed by the Student's $t$ test.

\section{Results}

\section{Cultures of premigratory neural crest}

Trunk neural crest was cultured in the presence and absence of $10^{-6} \mathrm{M}$ hydrocortisone or corticosterone. The ability of the cultures to convert $\left[{ }^{3} \mathrm{H}\right]$ tyrosine to $C A$ was assayed after 7 days. In agreement with our previous observations (Fauquet et al., 1981), cultures of crest alone produced only very small amounts of CA. As can be seen in Table I, supplementing the medium with glucocorticoid did not notably improve this synthetic ability.

Likewise, no cells of neuronal appearance were observed either in control or experimental cultures, and no CA-specific fluorescence was ever seen after glyoxylic acid fixation.

\section{Cultures of migrating neural crest associated with sclerotomal mesenchyme.}

Migrating trunk neural crest, which can be removed only in intimate association with the sclerotomal component of the somite of 3-day embryos, differentiates in culture into neuronlike cells that synthesize and store considerable amounts of CA (Fauquet et al., 1981). In contrast to premigratory neural crest, this embryonic system was found to be responsive to glucocorticoid hormones in vitro. When hydrocortisone or corticosterone, at a concentration of $10^{-6} \mathrm{M}$, was added at the beginning of the culture period, a 2- to 3 -fold stimulation of CA synthesis and accumulation could be measured radiochemically 7 days 


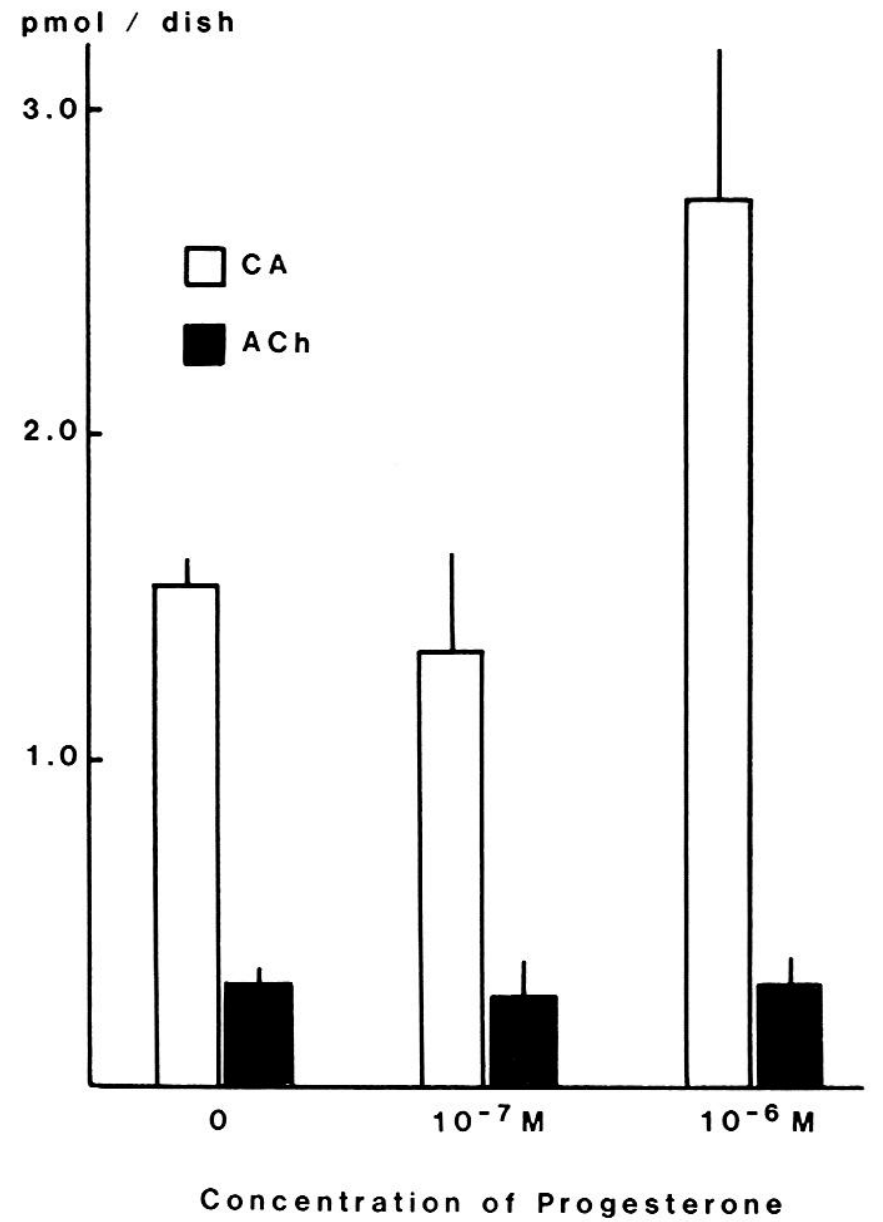

Figure 4. Effect of progesterone on neurotransmitter synthesis and accumulation in neural crest/sclerotome cultures. Cultures were grown for 7 days in media containing the indicated concentrations of progesterone. Production of $\mathrm{CA}$ and $\mathrm{ACh}$ was determined in each culture. Results are the means \pm SEM of values obtained in three to six experiments with each concentration of hormone. The quantity of CA produced by cultures treated with $10^{-6} \mathrm{M}$ progesterone differs significantly from the control $(p<0.05)$.

later. On the other hand, the synthesis of ACh was not modified by the presence of the steroid (Table II). Subsequent experiments were designed to study this hormonal effect in greater detail.

Biochemical aspects. Under control culture conditions, in the absence of exogenous steroid, NE and dopamine (DA) were synthesized, with a constant predominance of the former. After addition of hydrocortisone or corticosterone, the synthesis and accumulation of both of these CAs were increased. Although NE remained the major labeled product, the elaboration of DA was preferentially stimulated (Table III). This observation could be quantified in terms of the molar ratio of NE to DA, which was consequently diminished after hormone treatment. Although synthesis of $\mathrm{E}$ was barely measurable (less than $1 \%$ of total CA production) in control neural crest/sclerotome cultures, a small (about $2 \%$ of the total CA formed) but significant amount could be detected after exposure to glucocorticoid (Fig. 1).

The minimal concentration of hydrocortisone producing a reproducible effect on total (NE + DA) CA synthesis and accumulation was $10^{-7} \mathrm{M}$, and the peak stimulation was obtained at $10^{-6} \mathrm{M}$ (Fig. 2). Identical results were obtained with corticosterone. Lower concentrations of either compound failed to produce a consistent response. However, the synthetic glu-
TABLE IV

Effect of various concentrations of dexamethasone and corticosterone on the relative proportions of $N E$ and DA synthesized in cultured neural crest/sclerotome

The synthesis of CA during a 4 -hr incubation with $\left[{ }^{3} \mathrm{H}\right]$ tyrosine is expressed as the molar ratio of newly formed NE and DA. The analyses were performed by electrophoresis, but no correction has been made for the 2 to $3 \%$ contribution of $\mathrm{E}$ to "NE" radioactivity.

\begin{tabular}{lc}
\hline & $\begin{array}{c}\text { Molar Ratio } \\
{\left[{ }^{3} \mathrm{H}\right] \mathrm{NE} /\left[{ }^{3} \mathrm{H}\right] \mathrm{DA}}\end{array}$ \\
\hline Control $(n=8)$ & $21.4 \pm 5.0$ \\
$+10^{-8} \mathrm{M}$ Dexamethasone $(n=3)$ & $4.2 \pm 1.3$ \\
$+10^{-7} \mathrm{M}$ Dexamethasone $(n=3)$ & $4.4 \pm 0.2$ \\
$+10^{-6} \mathrm{M}$ Dexamethasone $(n=6)$ & $4.4 \pm 0.7$ \\
& \\
Control $(n=9)$ & $13.3 \pm 2.4$ \\
$+10^{-8} \mathrm{M}$ Corticosterone $(n=9)$ & $11.8 \pm 2.6$ \\
$+10^{-7} \mathrm{M}$ Corticosterone $(n=3)$ & $5.5 \pm 0.7$ \\
$+10^{-6} \mathrm{M}$ Corticosterone $(n=6)$ & $3.6 \pm 0.6$ \\
\hline
\end{tabular}

TABLE V

Effect of nonglucocorticoid steroid hormones on the relative proportions of NE and DA synthesized in cultured neural crest/sclerotome For details, see legend to Table IV.

\begin{tabular}{lc}
\hline & $\begin{array}{c}\text { Molar Ratio } \\
\left.\left[{ }^{3} \mathrm{H}\right] \mathrm{NE} /{ }^{3} \mathrm{H}\right] \mathrm{DA}\end{array}$ \\
\hline Control $(n=6)$ & $16.4 \pm 1.7$ \\
$+10^{-6} \mathrm{M}$ Progesterone $(n=6)$ & $26.5 \pm 4.7$ \\
& \\
Control $(n=4)$ & $13.8 \pm 1.5$ \\
$+10^{-6} \mathrm{M}$ Testosterone $(n=3)$ & $21.1 \pm 6.5$ \\
$+10^{-6} \mathrm{M}$ Estradiol $(n=4)$ & $30.5 \pm 7.0$ \\
\hline
\end{tabular}

TABLE VI

Effect of gonadal hormones on neurotransmitter synthesis in cultured neural crest/sclerotome

Cultures were grown for 7 days in the presence or absence of the indicated sex hormones. Results are expressed as femtomoles of $\mathrm{CA}$ and $\mathrm{ACh}$ produced per dish from $\left[{ }^{3} \mathrm{H}\right]$ tyrosine and $\left[{ }^{3} \mathrm{H}\right]$ choline during a 4-hr incubation.

\begin{tabular}{|c|c|c|}
\hline & \multicolumn{2}{|c|}{$\begin{array}{l}\text { Neurotransmitter } \\
\text { Synthesized }\end{array}$} \\
\hline & $\mathrm{CA}$ & $\mathrm{ACh}$ \\
\hline & \multicolumn{2}{|c|}{$\mathrm{fmol} / \mathrm{dish}$} \\
\hline $\begin{array}{l}\text { Control }(n=4) \\
+10^{-6} \mathrm{M} \text { Testosterone }(n=3) \\
+10^{-6} \mathrm{M} \text { Estradiol }(n=4)\end{array}$ & $\begin{aligned} 1107 & \pm 119 \\
747 & \pm 155 \\
550 & \pm 29\end{aligned}$ & $\begin{array}{c}943 \pm 194 \\
638 \pm 38 \\
1009 \pm 289\end{array}$ \\
\hline
\end{tabular}

cocorticoid dexamethasone was active at $10^{-8} \mathrm{M}$ (not shown). It is possible to illustrate the effect of these steroids in an alternative manner by comparing the molar ratios of newly formed $\mathrm{NE}$ and DA in the corresponding cultures. As can be seen in Table IV, NE/DA ratios differed in control and hormonetreated cultures by as much as 5 -fold. These values, presumably independent of the number of neuronal cells present, often proved to be a more sensitive reflection of glucocorticoid action than did overall CA production, which was subject to inevitably large individual variations.

At a concentration of $10^{-6} \mathrm{M}$, various glucocorticoids produced quantitatively similar effects on total CA synthesis, resulting on average in a 2 - to 3 -fold increase (Fig. 3 ). Note that cortexolone, which can, in some cases (see the "Discus- 

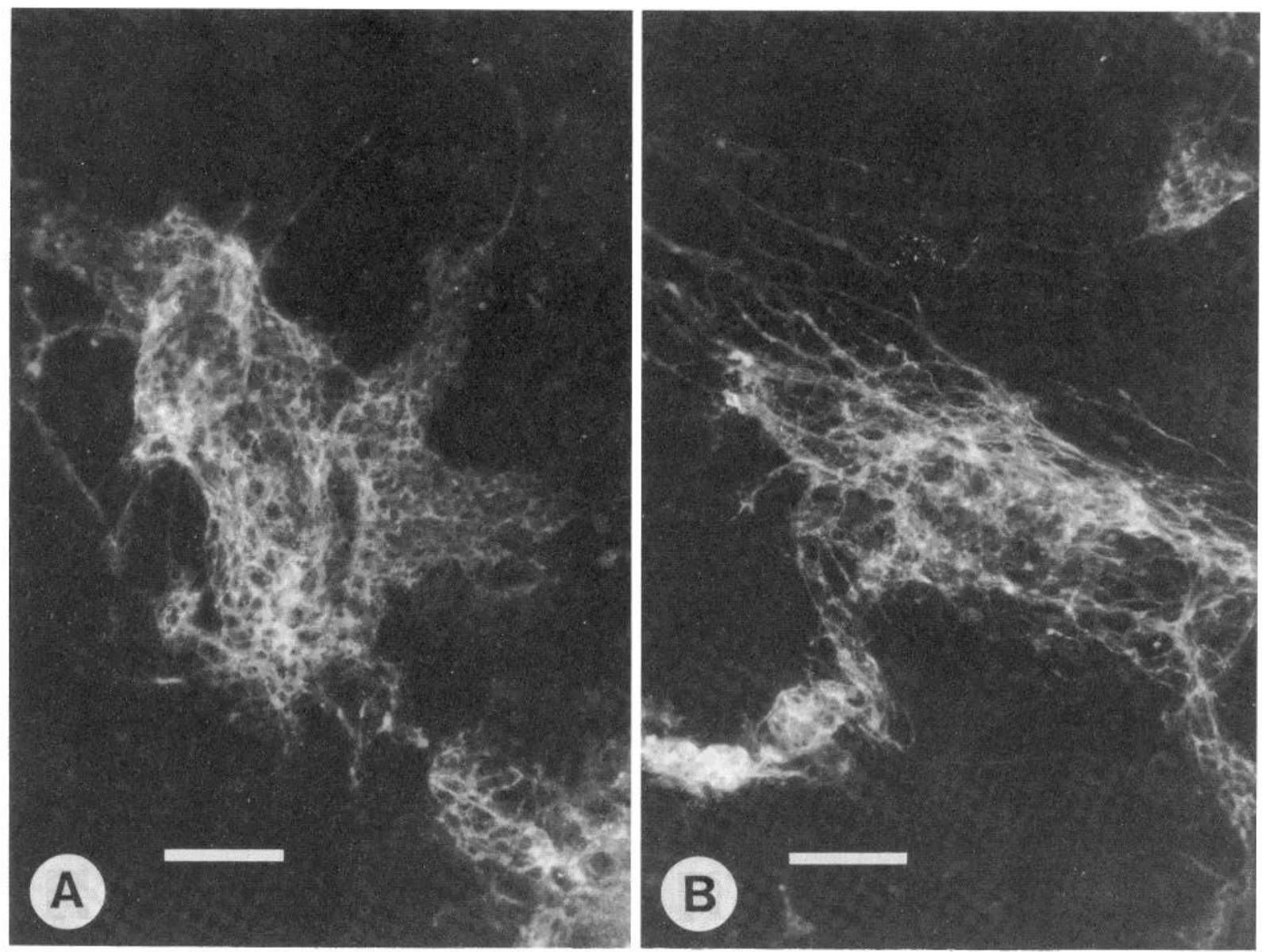

Figure 5. Fluorescence due to CA in cells differentiating in cultures of neural crest/sclerotome in the presence and absence of exogenous corticosterone. Cultures were grown on coverslips in control medium $(A)$ or in medium supplemented with $10^{-6} \mathrm{M}$ corticosterone $(B)$ for 7 days, then rinsed and treated with glyoxylic acid as described under "Materials and Methods." Scale bar $=100 \mu \mathrm{m}$.

sion"), act as a glucocorticoid antagonist, elicited a positive response in this system. It was striking that none of the hormones tested modified ACh production. Although significant stimulation of $\mathrm{CA}$ synthesis and storage could not be observed after less than 7 days in the steroid-containing medium, an appreciable lowering of the NE/DA ratio was first demonstrable 2 to 3 days after the start of hormone treatment. This was so whether the steroid was added at once or after several days of culture.

A number of nonglucocorticoid steroid hormones were also examined. At $10^{-6} \mathrm{M}$, progesterone stimulated CA production but was without effect at $10^{-7} \mathrm{M}$ (Fig. 4). However, comparison of NE/DA ratios (Tables IV and V) shows that, whereas glucocorticoid-treated cultures were all characterized by similar, low values, those for cultures grown in the presence of $10^{-6} \mathrm{M}$ progesterone were as high as or higher than control ratios. Progesterone was the only hormone examined that augmented total CA production without concomitantly decreasing the NE/ DA ratio. The gonadal steroids, testosterone and estradiol, at $10^{-6} \mathrm{M}$ did not increase CA synthesis and accumulation (Table VI). In fact, estradiol treatment apparently produced the opposite effect, although this initial observation has not been pursued. Neither of the sex hormones reduced NE/DA (Table V).

Cytochemistry and ultrastructure. The morphology and fine structure of crest cells developing in association with the sclerotomal mesenchyme in culture have been described in detail previously (Fauquet et al., 1981). Briefly, within a few days, phase-bright neuron-like cells can be seen, either in small groups or aggregated into larger, ganglion-like formations and linked to similar structures by numerous long fibers. Positive reaction for a number of characteristic immunological or cytochemical markers, together with the results of ultrastructural examination, suggests that a large number of cells in these cultures are indeed young adrenergic neurons.

Grown in the presence of $10^{-6} \mathrm{M}$ glucocorticoid (hydrocortisone or corticosterone), the gross morphology of the cultures was not notably modified. Similarly, reaction with glyoxylic acid did not reveal any consistent differences. Cell bodies, fibers, and varicosities all displayed fluorescence to varying degrees in experimental and control cultures (Fig. 5). However, the effect of hormone treatment was immediately obvious at the ultrastructural level after permanganate fixation. In control cultures, many small (mean diameter approximately $60 \mathrm{~nm}$ ) dense-core vesicles were found both in processes and in the cell bodies of neuron-like cells. Some cells possessed much larger vesicles (diameter up to $170 \mathrm{~nm}$ ), and yet others contained a mixed population. After hydrocortisone treatment, the number of CA storage vesicles in sections of neuronal cell bodies cut through the nucleus was greater than in similar cells from control cultures. Even more strikingly, both in perikarya and processes, their size was considerably increased. This phenomenon appeared to affect all of the granule-containing cells. In marked contrast to observations made under control conditions, no such cell was ever found to contain exclusively smallsized vesicles (up to $60 \mathrm{~nm}$ in diameter) after hormone treatment. Indeed, in certain cells and processes (Fig. 6), virtually no small-diameter vesicles were observed at all after exposure 

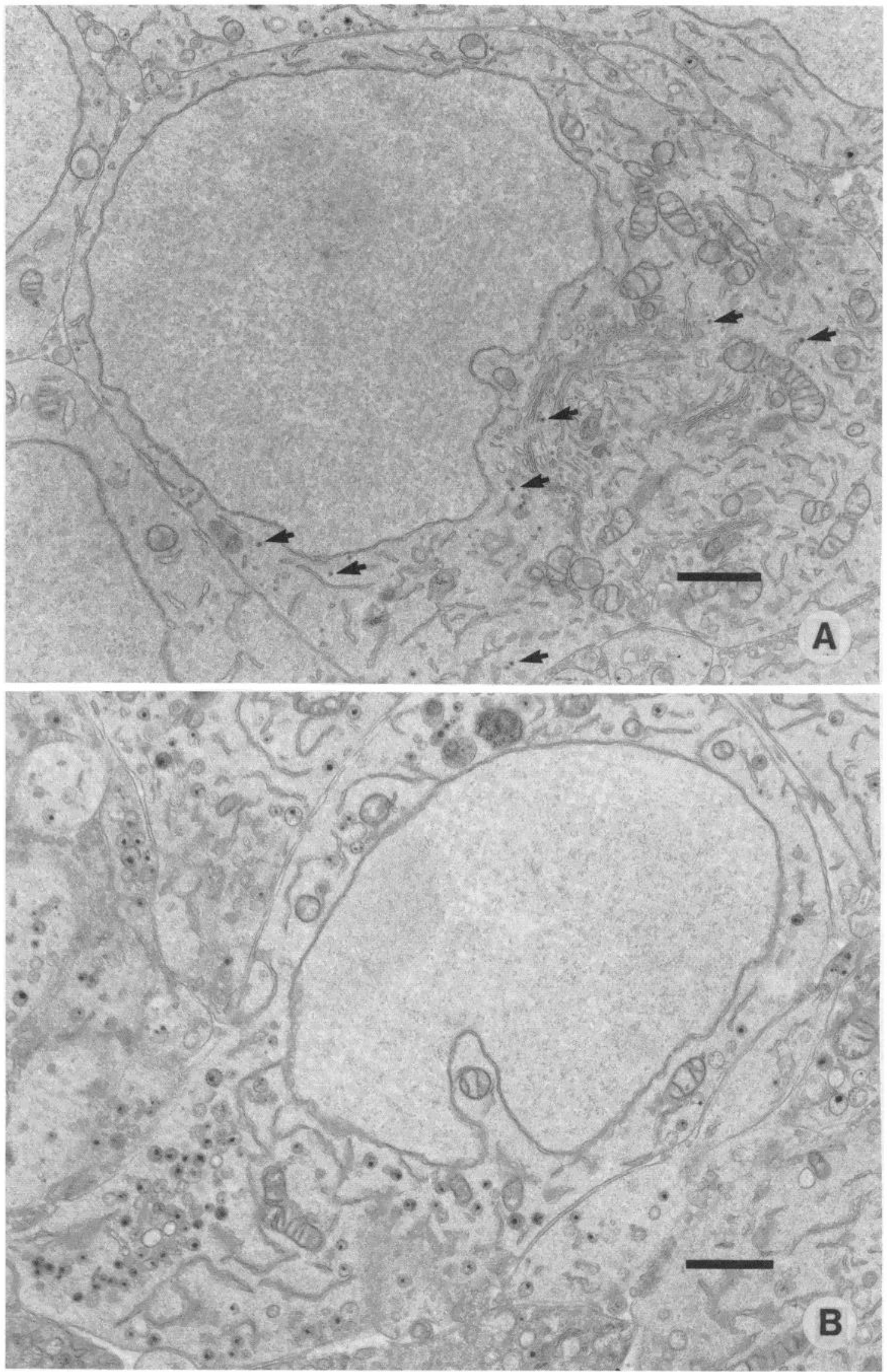

Figure 6. Dense-core vesicles in cell bodies and processes after permanganate fixation of 7-day cultures of neural crest/sclerotome. $A$, Cell body in control culture. Arrows indicate small, dense-core vesicles. Scale bar $=1 \mu \mathrm{m} . B$, Cell body in culture treated with $10^{-6} \mathrm{M}$ hydrocortisone. CA-containing vesicles are of considerably greater diameter. Scale bar $=1 \mu \mathrm{m}$. $C$, Processes in control culture showing small, dense-core vesicles. Scale bar $=250 \mathrm{~nm} . D$, Processes in culture treated with $10^{-6} \mathrm{M}$ hydrocortisone showing much larger vesicles. Scale bar $=250 \mathrm{~nm}$. 

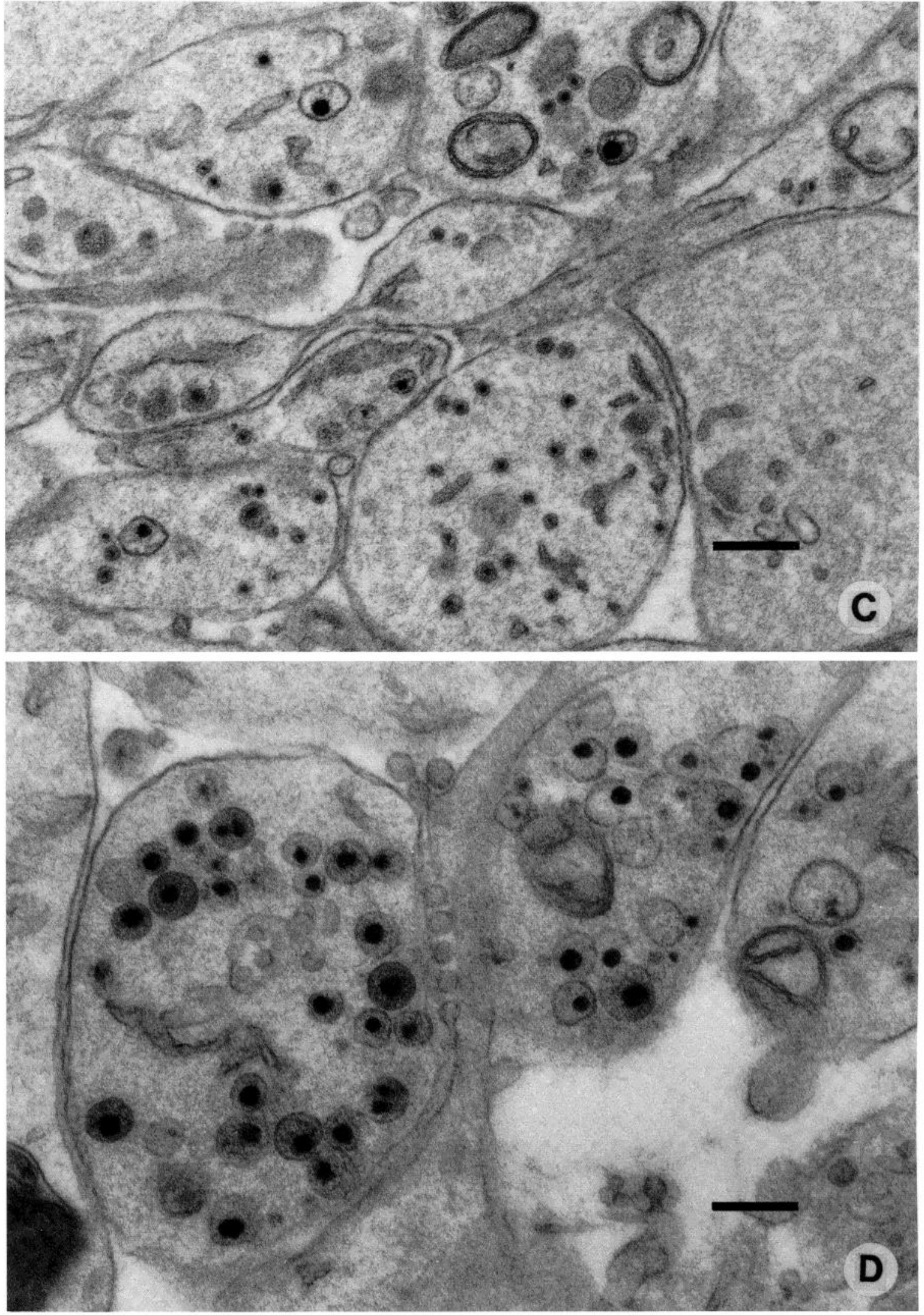

Figure 6, C and D 


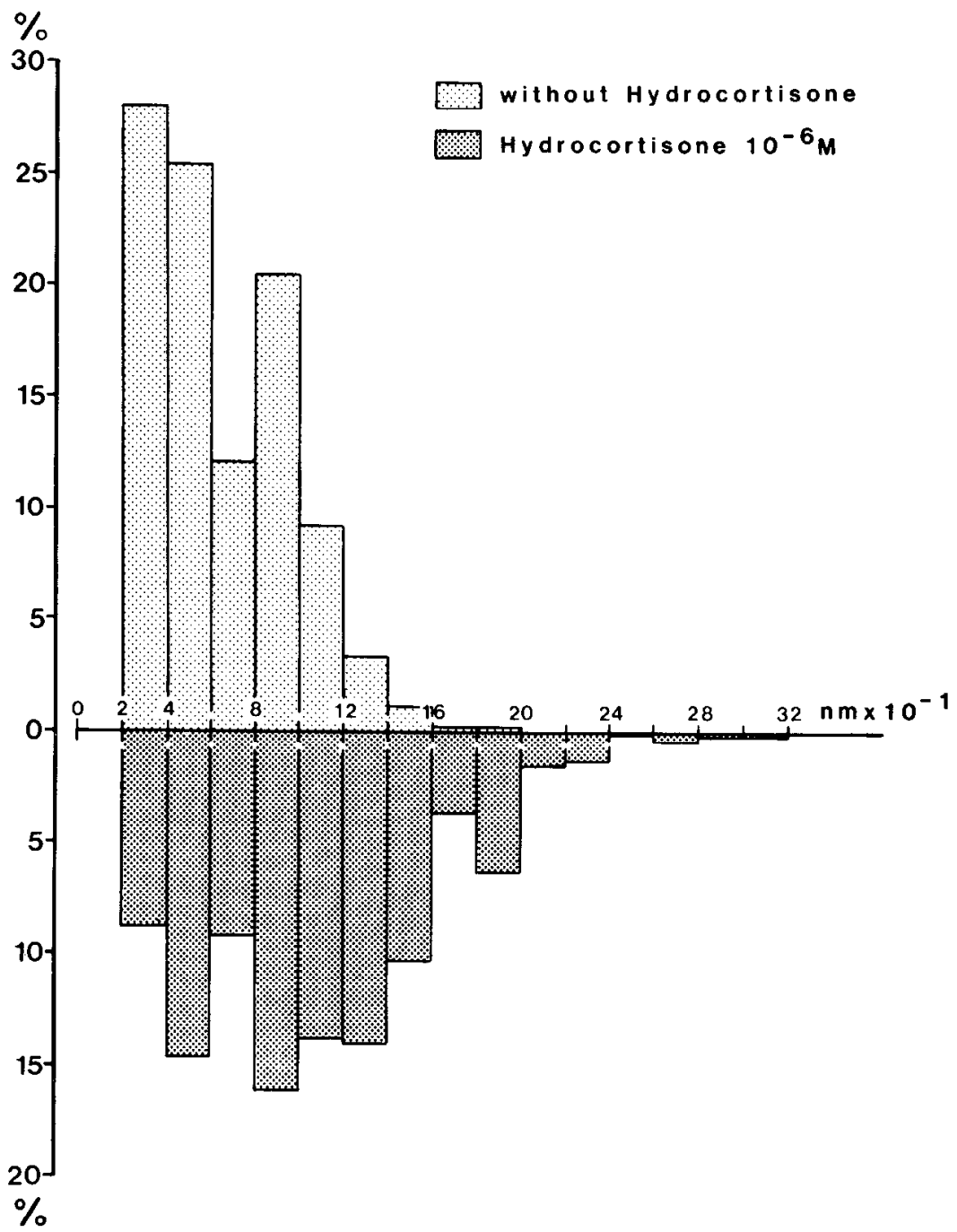

Figure 7. Distribution of vesicle diameters in cells differentiating in control and glucocorticoid-treated cultures of neural crest/sclerotome. Diameters of dense-core vesicles were determined in cell bodies and processes on several different electron micrographs of control and hydrocortisone-treated cultures. The results are expressed as the percentage of vesicles falling within a given 20-nm diameter range. The bar graphs show that large vesicles $(>120 \mathrm{~nm})$ constituted only $5 \%$ of the population in neurons differentiating in the absence of exogenous steroids, whereas their proportion rose to over $40 \%$ in cells grown for 7 days with $10^{-6} \mathrm{M}$ hydrocortisone. Conversely, the smallest vesicles (less than $60 \mathrm{~nm}$ in diameter) were relatively more abundant in control than in hormone-treated cultures $(55 \%$ and $23 \%$ of the population, respectively). Number of vesicles counted: control cultures, $n=1030$; hydrocortisone-treated cultures, $n=1026$.

to glucocorticoid. A global analysis of the distribution of vesicle sizes (in cell bodies and cytoplasmic prolongations) in control and hormone-treated cultures is presented in Figure 7.

Effect of steroid removal on adrenergic differentiation in $\mathrm{mi}$ grating neural crest/sclerotome cultures. Having established that glucocorticoids can modify adrenergic development of quail neural crest cells by increasing their capacity to synthesize and store $\mathrm{CA}$, we sought to determine whether the extensive adrenergic differentiation occurring in neural crest/sclerotome cultures in the absence of added glucocorticoids was, in fact, caused by the presence of such hormones in the serum or embryo extract used to supplement the medium. Therefore, we cultured these embryonic rudiments in medium containing serum and embryo extract from which endogenous steroids had been removed by treatment with charcoal. As can be seen from Table VII, adrenergic differentiation, characterized by CA synthesis after 7 days in vitro, was reduced by about $30 \%$ under these conditions; however, this decrease was not statistically significant.

Co-cultures of premigratory neural crest with somites and notochord. The results presented above demonstrate that adrenergic differentiation in vitro of neural crest cells that have migrated to the sclerotomal component of the somite can be stimulated by exogenous glucocorticoids, whereas premigratory crest is unresponsive. However, it is not clear whether this positive reaction reflects the maturation of the crest cells or the presence of a favorable environment (the sclerotomal mesenchyme). Therefore, it was interesting to determine whether premigratory crest would also respond to glucocorticoid treatment if cultured in a suitable non-neural milieu. We have previously shown that, when the tips of trunk level neural folds are grown with somitic mesenchyme and notochord from 2-day 


\section{TABLE VII}

Effect of steroid removal on neurotransmitter synthesis in cultured neural crest/sclerotome

The synthesis and accumulation of $\mathrm{CA}$ and $\mathrm{ACh}$ were determined in cultures grown in control medium and in medium containing fetal calf serum and chick embryo extract from which endogenous steroids had been removed by charcoal extraction (see "Materials and Methods").

\begin{tabular}{|c|c|c|}
\hline & \multicolumn{2}{|c|}{$\begin{array}{l}\text { Neurotransmitter } \\
\text { Synthesized }\end{array}$} \\
\hline & $\mathrm{CA}$ & $\Lambda \mathrm{Ch}$ \\
\hline & \multicolumn{2}{|c|}{ fmol/dish } \\
\hline Control medium $(n=5)$ & $1252 \pm 136$ & $855 \pm 165$ \\
\hline Steroid-free medium $(n=5)$ & $864 \pm 96$ & $1283 \pm 292$ \\
\hline
\end{tabular}

quail embryos, they give rise after several days to cells that can synthesize measurable quantities of NE and DA. However, differentiation remains very incomplete, since few, if any, identifiable neurons develop, and tests for CA histofluorescence are negative (Fauquet et al., 1981).

A marked stimulation of CA production could be measured biochemically 7 days after adding hydrocortisone or corticosterone to such co-cultures. 'The amount of CA synthesized and stored was as much as 12 times higher than in control cultures (Table VIII). Both in the presence and absence of the glucocorticoids, the predominant radioactive CA was $\mathrm{NE}$; DA was also produced, but HPLC analysis revealed no E. The synthesis of ACh was not modified by treatment with the hormone. This selective enhancement of adrenergic differentiation was found, cytochemically, to correspond to the development of CA stores that could be visualized after reaction with glyoxylic acid. In marked contrast to control cultures grown in the absence of exogenous hormone, many fluorescent cell bodies and processes could be seen, singly or in clusters, in glucocorticoid-treated premigratory neural crest co-cultures (Fig. 8).

\section{Discussion}

Since Lempinen (1964) showed that administration of cortisone or hydrocortisone to newborn rats prevented the normal postnatal disappearance of extra-adrenal chromaffin tissue and also caused chromaffin cells to appear in the sympathetic ganglia, numerous workers have demonstrated a variety of effects of glucocorticoid hormones on adrenergic derivatives of the neural crest, both in vivo and in culture. However, extremely little is known of the influences of these steroids on the very earliest stages of catecholaminergic cell development. In the present study, we show that the adrenergic differentiation of avian neural crest in vitro can be stimulated selectively by the addition of certain steroids to the medium. This effect has been observed both in premigratory and migrating crest grown in the presence of somite or somite-derived tissue. Biochemical, cytochemical, and ultrastructural analysis of this phenomenon in cultures of sclerotome-associated migrating trunk crest (which, in contrast to neural fold, can be obtained in relatively large quantities without undue difficulty) showed the principal result to be a significant increase in the synthesis and storage both of $\mathrm{NE}$ and DA, corresponding to a marked augmentation in the number and size of CA-containing vesicles.

Comparison of the efficacy of different steroids demonstrated the natural glucocorticoids, hydrocortisone and corticosterone, their metabolite, cortexolone, and their synthetic analogue, dexamethasone, to be potent stimulators of CA production. Optimal effects were obtained at $10^{-6} \mathrm{M}$, although a response could be measured at concentrations at least 10 -fold lower. Although testosterone and estradiol were inactive, the fact that progesterone was stimulatory in this system indicates that the

\section{TABLE VIII}

Effect of hydrocortisone and corticosterone on neurotransmitter synthesis in co-cultures of neural crest/somite/notochord

Premigratory neural crest, associated with somite and notochord, as described under "Materials and Methods," was cultured in the presence and absence of exogenous glucocorticoid. Neurotransmitter synthesis and accumulation were determined 7 days later.

\begin{tabular}{|c|c|c|}
\hline & \multicolumn{2}{|c|}{$\begin{array}{l}\text { Neurotransmitter } \\
\text { Synthesized }\end{array}$} \\
\hline & $\mathrm{CA}$ & ACh \\
\hline & \multicolumn{2}{|c|}{$\mathrm{fmol} / \mathrm{dish}$} \\
\hline $\begin{array}{l}\text { Control }(n=12) \\
+10^{-6} \text { M Hydrocortisone }(n=5)\end{array}$ & $\begin{array}{c}53 \pm 18 \\
202+55^{a}\end{array}$ & $\begin{array}{l}75 \pm 9 \\
87 \pm 9\end{array}$ \\
\hline $\begin{array}{l}\text { Control }(n=5) \\
+10^{-6} \text { M Corticosterone }(n=6)\end{array}$ & $\begin{aligned} 20 & \pm 10 \\
244 & \pm 69^{b}\end{aligned}$ & $\begin{array}{r}80 \pm 16 \\
115 \pm 31\end{array}$ \\
\hline
\end{tabular}

${ }^{a}$ Differs significantly from the control $(p<0.02)$.

${ }^{b}$ Differs significantly from the control $(p<0.05)$.

effect is not exclusive to glucocorticoids. Although progesterone is able to bind to glucocorticoid receptors (Rousseau et al., 1972, 1973; Markey et al., 1982), it has been found to have no, or negligible, agonist activity for a number of glucocorticoid-mediated phenomena (e.g., Melnykovych and Bishop, 1969; Samuels and Tomkins, 1970; Schonbrum, 1982), including the elevation of tyrosine hydroxylase (TH) levels in mouse locus ceruleus in vivo (Markey et al., 1982) or in rat pheochromocytoma cultures (Lucas and Thoenen, 1977). However, it should be noted that, in our cultures, all of the glucocorticoids testedbut not progesterone-modified the NE/DA ratio of newly synthesized CA (Tables III, IV, and V), suggesting that the two classes of hormones produce their effects by independent mechanisms.

Like progesterone, cortexolone can compete with glucocorticoids for cytoplasmic receptors (Turnell et al., 1974; Coutard et al., 1979). However, while acting as a glucocorticoid antagonist in certain situations (Hanbauer et al., 1975; Cutler et al., 1979), it behaves as an agonist in others (Samuels and Tomkins, 1970; Rousseau et al., 1972; McEvoy and Hegre, 1976; Bohn et al., 1981; Jonakait et al., 1981). Although it has been suggested that the agonist effects of cortexolone are due to its metabolic conversion to hydrocortisone in vivo (Cutler et al., 1979), it is possible that the 11-deoxysteroid itself possesses glucocorticoid activity (Samuels and Tomkins, 1970).

Many workers using a number of different experimental systems have described glucocorticoid-evoked increases in the catalytic activity and/or intensity of immunohistochemical reaction of enzymes required for CA biosynthesis. These steroids were found to stimulate TH activity in sympathetic ganglia of adult rats in vivo (Hanbauer et al., 1975), in explant cultures of sympathetic ganglia from adult or newborn rats (Otten and Thoenen, 1976a; Nagaiah et al., 1977; McLennan et al., 1980), in the CA-containing small intensely fluorescent (SIF) cells in vivo (Eränkö et al., 1982), and in cultures of pheochromocytoma (Lucas and Thoenen, 1977; Otten and Towbin, 1980; Schubert et al., 1980) and neuroblastoma cells (Williams et al., 1981). This hormonal response has been shown, in the clonal PC 12 line, to be due to an increase in the rate of synthesis of the enzyme protein, which is itself consequent upon a stimulation of TH mRNA activity (Baetge et al., 1981). Similarly, dopamine $\beta$-hydroxylase activity is stimulated by glucocorticoids in sympathetic ganglia in vitro (Otten and Thoenen, 1976a) and in SIF cells in vivo (Eränkö et al., 1982). Finally, administration of these hormones leads to increased intensity of phenylethanolamine- $N$-methyltransferase (PNMT) immunoreactivity in the adrenal medulla of the fetal rat (Bohn et al., 1981) and, 


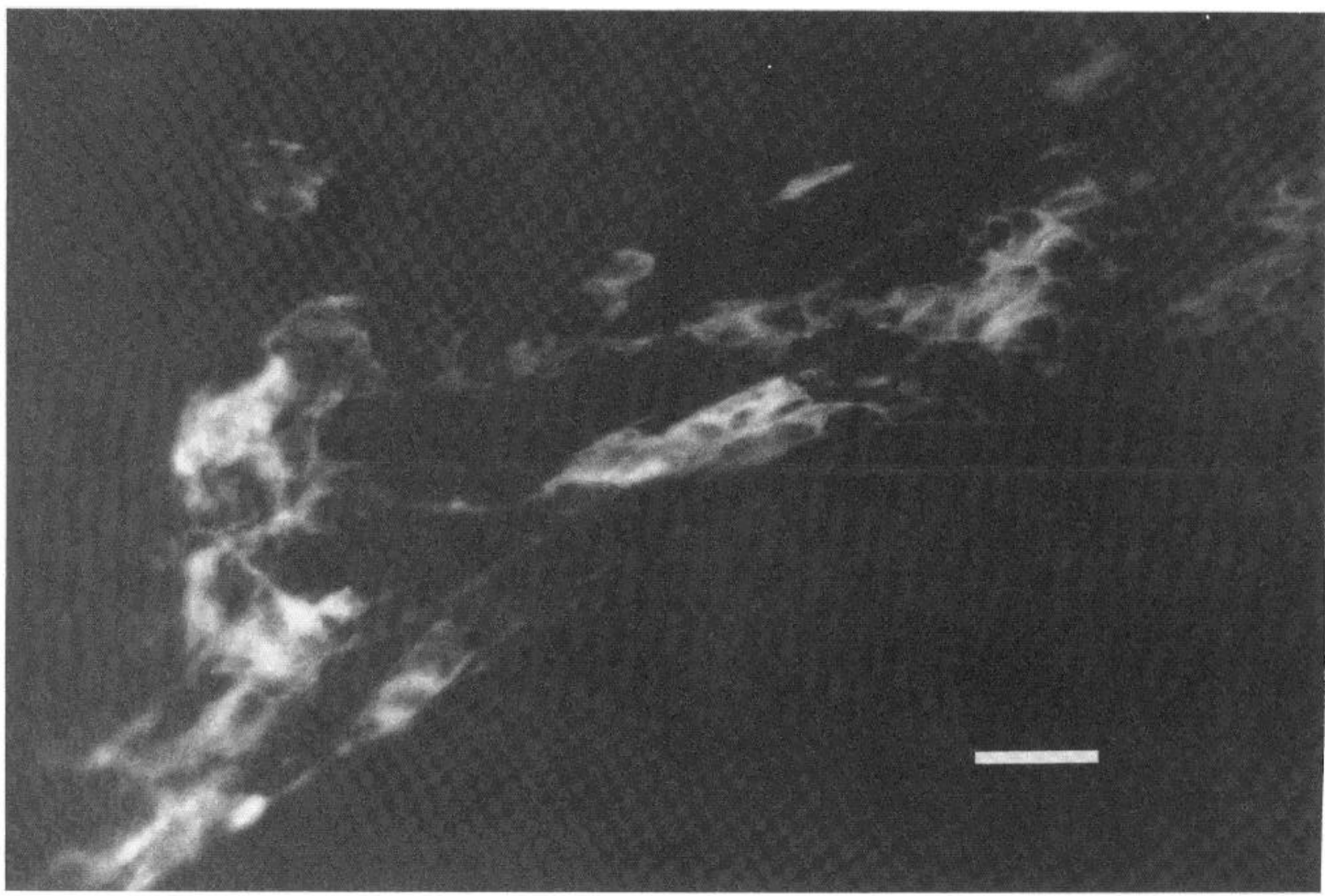

Figure 1. Fluorescence of endogenous CA in cells differentiating in cultures of premigratory neural crest grown with somite and notochord in the presence of $10^{-6} \mathrm{M}$ hydrocortisone. Cultures were treated with glyoxylic acid 7 days after adding the hormone. Histofluorescence was not observed in cultures grown in the absence of exogenous glucocorticoid. Scale bar $=30 \mu \mathrm{m}$.

likewise, to the appearance of the enzyme in extra-adrenal chromaffin tissue and in SIF cells of sympathetic ganglia, both in the fetus (Bohn et al., 1982) and in the newborn animal (Eränkö et al., 1982). An increase in PNMT catalytic activity has also been demonstrated in vitro, in explants of newborn rat sympathetic ganglia (Phillipson and Moore, 1975) and in fetal rat adrenal medullary cell cultures (Teitelman et al., 1982).

Although the activities of the different enzymes involved in the CA synthetic pathway were not measured individually in our study, the modification by glucocorticoids of the relative proportions of NE and DA produced by neural crest/sclerotome cultures was similar to that resulting from stimulation of TH activity in PC 12 cells (Tischler et al., 1983). In addition to possible changes in the activity of CA-forming enzymes, an expansion of the intracellular pool of CA following glucocorticoid treatment was clearly revealed by our biochemical data and was corroborated by the results of ultrastructural analysis, which demonstrated a striking increase in the number and, more particularly, the size of dense-core vesicles. Similar effects of glucocorticoids on CA storage granules have been observed both in vitro and in vivo, in other adrenergic cells (Hervonen and Eränkö, 1975; Eränkö and Eränkö, 1980; Schubert et al., 1980; Chiba et al., 1981; Williams et al., 1981; Tischler et al., 1983). It is of interest that we could detect significantly increased accumulation of newly synthesized CA only after a week's culture with glucocorticoids, whereas the modification in the relative rates of production of $\mathrm{NE}$ and DA was discernible within 2 to 3 days of initiating hormone treatment. Thus, relative to the response of CA-synthesizing enzymes to glucocorticoids, acquisition of extended CA storage capacity appears to be a comparatively protracted process. It is worthy of mention in this respect that increased storage is not an automatic consequence of increased CA synthesis, for treatment with a number of different agents (other than glucocorticoids) can produce a stimulation of $\mathrm{TH}$ activity without any concomitant effect on CA accumulation (Tischler et al., 1983).

It should be noted that, although glucocorticoids do appear to act directly on certain adrenergic cells (Schubert et al., 1980 Baetge et al., 1981; Tischler et al., 1983), it cannot be excluded that, in heterogeneous culture systems, the non-neural cells in the population are involved in the response of adrenergic derivatives of the neural crest to hormone. Indeed, the fact that corticosteroids, in some circumstances, stimulate $\mathrm{TH}$ activity only in association with additional elements, such as nerve growth factor (Otten and Thoenen, 1976b; Nagaiah et al., 1977; Otten and Towbin, 1980) or intact preganglionic innervation (Hanbauer et al., 1975; Otten and Thoenen, 1976a), indicates that their action on CA metabolism is not necessarily always simple and direct. Our finding that glucocorticoids produce no detectable effect on premigratory neural crest unless it is cultured in the presence of other cell types (cf. Tables I and VIII) suggests that the latter may, in fact, be the initial target, although an alternative explanation is that the crest cells become receptive to hormone only after maturation in the presence of non-neural tissue. If glucocorticoids do stimulate catecholaminergic differentiation indirectly, it seems unlikely that this stems from a general increase in cell density, which has been shown to result in elevated TH activity in pheochromocytoma cells (Lucas et al., 1979). First, no hormonally directed increase in total protein content was found in any of the types of culture studied (J. Smith and M. Fauquet, unpublished results); and, second, the stimulation of $\mathrm{CA}$ synthesis and accumulation brought about by glucocorticoids in neural crest/ somite/notochord co-cultures could not be mimicked by cultur- 
ing crest with 2 to 3 times the usual amount of noncrest tissue (results not shown). It seems more probable that any changes in the non-neural components of the cultures are of a qualitative nature. A number of situations have been described in which glucocorticoids modify the production by one cell type of a factor that acts on a second class of cells (e.g., Smith, 1979; Fukada, 1980). Interactions of this sort could well play a part in the stimulation of CA-related properties observed in our cultures. In this connection, it is of interest that glucocorticoids increase the production by fibroblasts of fibronectin (Oliver et al., 1983), a glycoprotein that is able to stimulate adrenergic differentiation in neural crest grown in vitro (Sieber-Blum et al., 1981; Loring et al., 1982).

Whatever the mechanism of glucocorticoid action on neural crest proves to be, our results provide no evidence that these hormones act as initiators of adrenergic differentiation; it seems more likely that their role consists in enhancing the relevant properties in cells that have already been subjected to a triggering signal of another nature. The principal argument resides in the fact that, under conditions of culture that do not allow appreciable development of CA-synthesizing cells in the absence of exogenous hormone, i.e., culture of premigratory trunk neural crest alone, addition of glucocorticoid does not produce any neasurable improvement in adrenergic differentiation. Furthermore, extensive "spontaneous" differentiation can take place in migrating neural crest/sclerotome in medium devoid of steroids (Table VII). Thus, the initial expression of catech= olaminergic properties in vitro appears to be independent of glucocorticoids. However, once a certain "basal" level of differentiation has been achieved, e.g., in the case of premigratory crest, after culture with somites and notochord, the hormones can exert an important stimulatory effect on CA synthesis and storage. Similar conclusions have been reached concerning the role of glucocorticoids in PNMT expression in the adrenal gland (Bohn et al., 1981, 1982; Teitelman et al., 1982).

ACh synthesis is an early feature of neural crest cells in vivo, and this property persists in vitro, even under conditions that favor extensive differentiation of adrenergic cells (Smith et al., 1979; Fauquet et al., 1981). In cultures of sympathetic ganglia from newborn rat or of PC 12 cells, glucocorticoid treatment diminishes choline acetyltransferase activity while increasing $\mathrm{TH}$ levels, and it has been suggested that corticosteroids could act in a similar way to control neurotransmitter choice in developing sympathetic neurons in vivo (McLennan et al., 1980; Schubert et al., 1980). However, in all of the experiments described here, ACh production was consistently unaffected by exposure of the cultures to hormone, suggesting that this mechanism does not apply at least to the earliest stages of the development of avian neuronal precursors.

On the other hand, it might be speculated that the action of corticosteroids on developing neuroblasts concerns, not the selection of neurotransmitter, but the establishment and/or maintenance of phenotypic diversity within the adrenergic population itself. The neural crest gives rise to several types of catecholaminergic derivative (sympathetic neurons, SIF, and chromaffin cells), characterizable in part by the size of their CA storage vesicles. In mammals, SIF cell numbers increase dramatically after glucocorticoid treatment in vivo and in vitro (Eränkö and Eränkö, 1972, 1980; Eränkö et al., 1982), and evidence has been presented that primitive precursor cells are channeled along either the neuronal (small vesicles) or SIF/ chromaffin (large vesicles) pathway according to the ambient glucocorticoid levels (Landis and Patterson, 1981; Doupe and Patterson, 1982). It must he emphasized that the significance of the different types of CA-containing cells found in developing bird sympathetic ganglia and the relationships between them have not yet been satisfactorily clarified (Jacobowitz and Green, 1974; Hervonen and Eränkö, 1975; Luckenbill-Edds and van Horn, 1980). However, the marked hormone-dependent increase in $\mathrm{CA}$ vesicle diameter observed in our experiments suggests that glucocorticoids could mediate similar phenotypic interconversions in the avian species also. Furthermore, our findings indicate that neural crest derivatives would be potentially receptive, directly or indirectly, to corticosteroids at the moment they undergo gangliogenesis, i.e., when a number of important developmental processes are presumably set in motion. Whether hormones do, in fact, intervene in vivo at such early embryonic stages is the object of current investigation in our laboratory.

\section{References}

Armelin, A. H., K. Nishikawa, and G. H. Sato (1974) Control of mammalian cell growth in culture: The action of protein and steroid hormones as effector substances. In Control of Proliferation in Animal Cells, B. Clarkson and R. Baserga, eds., pp. 97-104, Cold Spring Harbor Laboratory, New York.

Asmus, P. A., and C. R. Freed (1979) Reversed-phase high-performance liquid chromatography of catecholamines and their congeners with simple acids as ion-pairing reagents. J. Chromatogr. 169: 303-311.

Baetge, E. E., B. B. Kaplan, D. J. Reis, and T. H. Joh (1981) Translation of tyrosine hydroxylase from poly (A)-mRNA in pheochromocytoma cells is enhanced by dexamethasone. Proc. Natl. Acad. Sci. U. S, A. 78: $1269-1273$.

Bohn, M. C., M. Goldstein, and I. B. Black (1981) Role of glucocorticoids in expression of the adrenergic phenotype in rat embryonic adrenal gland. Dev. Biol. 82: 1-10.

Bohn, M. C., M. Goldstein, and I. B. Black (1982) Expression of phenylethanolamine $N$-methyltransferase in rat sympathetic ganglia and extra-adrenal chromaffin tissue. Dev. Biol. 89: 299-308.

Chiba, T., Y. Murata, and T. Koike (1981) Plasticity of pheochromocytoma (PC 12) cells demonstrated by nerve growth factor or glucocorticoid treatment: A catecholamine fluorescence and electron microscopic investigation. Biomed. Res. 2: 618-628.

Cohen, A. M. (1972) Factors directing the expression of sympathetic nerve traits in cells of neural crest origin. J. Exp. Zool. 179: 167-182.

Costa, M., O. Eränkö, and L. Eränkö (1974) Hydrocortisone-induced increase in the histochemically demonstrable catecholamine content of sympathetic neurons of the newborn rat. Brain Res. 67: 457-466.

Coutard, M., M. -J. Asborne-Pellegrin, and J. Funder (1979) Autoradiographic localization of ${ }^{3} \mathrm{H}$-glucocorticoids and ${ }^{3} \mathrm{H}$-cortexolone in mouse pituitary. Cell Tissue Res. 200: 311-322.

Cutler, G. B., Jr., K. M. Barnes, M. A. Sauer, and D. L. Loriaux (1979) 11-Deoxycortisol: A glucocorticoid antagonist in vivo. Endocrinology 104: $1839-1844$.

Doupe, A. J., and P. H. Patterson (1982) Glucocorticoids and the developing nervous system. Curr. Top. Neuroendocrinol. 2: 23-43.

Eränkö, L., and O. Eränkö (1972) Fffect of hydrocortisone on histochemically demonstrable catecholamines in the sympathetic ganglia and extra-adrenal chromaffin tissue of the rat. Acta Physiol. Scand. 84: $125-133$.

Eränkö, O., and L. Eränkö (1980) Induction of SIF cells by hydrocortisone or human cord serum in sympathetic ganglia and their subsequent fate in vivo and in vitro. In Histochemisiry and Cell Bivlogy of Autonomic Neurons, SIF Cells and Paraneurons, O. Eränkö, S. Soinila, and H. Päivärinta, eds., pp. 17-26, Raven Press, New York. Eränkö, O., J. W. Heath, and L. Eränkö (1973) Effect of hydrocortisone on the ultrastructure of the small granule-containing cells in the superior cervical ganglion of the newborn rat. Experientia 29: 457459.

Eränkö, O., V. M. Pickel, M. Härkönen, L. Eränkö, T. H. Joh, and D. J. Reis (1982) Fiffect of hydrocortisone on catecholamines and the enzymes synthesizing them in the developing sympathetic ganglion. Histochem. J. 14: 461-478.

Fauquet, M., J. Smith, C. Ziller, and N. M. Le Douarin (1981) Differentiation of autonomic precursors in vitro: Cholinergic and adrenergic traits in cultured neural crest cells. J. Neurosci. 1: 478-492.

Fukada, K. (1980) Hormonal control of neurotransmitter choice in sympathetic neurone cultures. Nature 287: 553-555.

Hanbauer, I., A. Guidotti, and E. Costa (1975) Dexamethasone induces tyrosine hydroxylase in sympathetic ganglia but not in adrenal medulla. Brain Res. 85: 527-531. 
Hervonen, H., and O. Eränkö (1975) Fluorescence histochemical and electron microscopical observations on sympathetic ganglia of the chick embryo cultured with and without hydrocortisone. Cell Tissue Res. 156: 145-166.

Jacobowitz, D. M., and L. A. Greene (1974) Histofluorescence study of chromaffin cells in dissociated cell cultures of chick embryo sympathetic ganglia. J. Neurobiol. 5: 65-83.

Jonakait, G. M., M. C. Bohn, K. Markey, M. Goldstein, and I. B. Black (1981) Elevation of maternal glucocorticoid hormones alters neurotransmitter phenotypical expression in embryos. Dev. Biol. 88: 288296.

König, R. (1979) Consecutive demonstration of catecholamines and dopamine $\beta$-hydroxylase within the same specimen. Histochemistry 61: 301-305.

Landis, S. C., and P. H. Patterson (1981) Neural crest cell lineages. Trends Neurosci. 4: 172-175.

Le Douarin, N. M. (1982) The Neural Crest, Cambridge University Press, Cambridge, England.

Le Douarin, N. M., J. Smith, and C. Le Lièvre (1981) From the neural crest to the ganglia of the peripheral nervous system. Annu. Rev. Physiol. 43: 653-671.

Lempinen, M. (1964) Extra-adrenal chromaffin tissue of the rat and the effect of cortical hormones on it. Acta Physiol. Scand. 62 (Suppl. 231): 1-91.

Loring, J., B. Glimelius, and J. A. Weston (1982) Extracellular matrix materials influence quail neural crest differentiation in vitro. Dev. Biol. 90: 165-174.

Lucas, C. A., and H. Thoenen (1977) Selective induction by glucocorticoids of tyrosine hydroxylase in organ culturcs of rat pheochromocytoma. Neuroscience 2: 1095-1101.

Lucas, C. A., D. Edgar, and H. Thoenen (1979) Regulation of tyrosine hydroxylase and choline acetyltransferase activities by cell density in the PC 12 rat pheochromocytoma clonal cell line. Exp. Cell Res. 121: $79-86$.

Luckenbill-Edds, L., and C. van Horn (1980) Development of chick paravertebral sympathetic ganglia. I. Fine structure and correlative histofluorescence of catecholaminergic cells. J. Comp. Neurol. 191: 65-76.

Markey, K. A., A. C. Towle, and P. Y. Sze (1982) Glucocorticoid influence on tyrosine hydroxylase activity in mouse locus coeruleus during postnatal development. Endocrinology 111: 1519-1523.

McEvoy, R. C., and O. D. Hegre (1976) Foetal rat pancreas in organ culture. Effects of media supplementation with various steroid hormones on the acinar and islet components. Differentiation 6: 105111.

McLennan, I. S., C. E. Hill, and I. A. Hendry (1980) Glucocorticosteroids modulate transmitter choice in developing superior cervical ganglion. Nature 283: 206-207.

Melnykovych, G., and C. F. Bishop (1969) Relationships between steroid binding and elevation of alkaline phosphatase in HeLa cells. Biochim. Biophys. Acta 177: 579-585.

Nagaiah, K., P. MacDonnell, and G. Guroff (1977) Induction of tyrosine hydroxylase synthesis in rat superior cervical ganglia in vitro by nerve growth factor and dexamethasone. Biochem. Biophys. Res. Commun. 75: 832-837.

Norr, S. C. (1973) In vitro analysis of sympathetic neuron differentiation from chick neural crest cells. Dev. Biol. 31: 16-38.

Oliver, N., R. F. Newby, L. T. Furcht, and S. Bourgeois (1983) Regulation of fibronectin biosynthesis by glucocorticoids in human fibrosarcoma cells and normal fibroblasts. Cell 33: 287-296.

Otten, U., and H. Thoenen (1976a) Selective induction of tyrosine hydroxylase and dopamine $\beta$-hydroxylase in sympathetic ganglia in organ culture: Role of glucocorticoids as modulators. Mol. Pharmacol. 12: 353-361.
Otten, U., and II. Thoenen (1976b) Modulatory role of glucocorticoids on NGF-mediated enzyme induction in organ cultures of sympathetic ganglia. Brain Res. 111: 438-441.

Otten, U., and M. Towbin (1980) Permissive action of glucocorticoids in induction of tyrosine hydroxylase by nerve growth factor in a pheochromocytoma cell line. Brain Res. 193: 304-308.

Patterson, P. H. (1978) Environmental determination of autonomic neurotransmitter functions. Annu. Rev. Neurosci. 1: 1-17.

Dhillipson, O. T., and K. E. Moore (1975) Effects of dexamethasone and nerve growth factor on phenylethanolamine $N$-methyltransferase and adrenaline in organ cultures of newborn rat superior cervical ganglion. J. Neurochem. 25: 295-298.

Ross, D., M. Johnson, and R. Bunge (1977) Development of cholinergic characteristics in adrenergic neurons is age-dependent. Nature 267 . 536-539.

Rousseau, G. G., J. D. Baxter, and G. M. Tomkins (1972) Glucocorticoid receptors: Relations between steroid binding and biological effects. J. Mol. Biol. 67: 99-115.

Rousseau, G. G., J. D. Baxter, S. J. Higgins, and G. M. Tomkins (1973) Steroid-induced nuclear binding of glucocorticoid receptors in intact hepatoma cells. J. Mol. Biol. 79: 539-554.

Samuels, H. H., and G. M. Tomkins (1970) Relation of steroid structure to enzyme induction in hepatoma tissue culture cells. J. Mol. Biol. 52: $57-74$.

Sandquist, D., A. C. Black, Jr., S. K. Sahu, L. Williams, and T. H. Williams (1979) Dexamethasone induces increased catecholamine biosynthesis in cultured neuroblastoma. Exp. Cell Res. 123: 417-421.

Schonbrunn, A. (1982) Glucocorticoids down-regulate somatostatin receptors on pituitary cells in culture. Endocrinology 110: 11471154 .

Schubert, D., M. LaCorbiere, F. G. Klier, and J. H. Steinbach (1980) The modulation of neurotransmitter synthesis by steroid hormones and insulin. Brain Res. 190:67-69.

Sieber-Blum, M., F. Sieber, and K. M. Yamada (1981) Cellular fibronectin promotes adrenergic differentiation of quail neural crest in vitro. Exp. Cell Res. 133: 285-295.

Smith, B. T. (1979) Lung maturation in the fetal rat: Acceleration by injection of fibroblast-pneumocyte factor. Science 204: 1094-1095.

Smith, J., M. Fauquet, C. Ziller, and N. M. Le Douarin (1979) Acetylcholine synthesis by mesencephalic neural crest in the process of migration in vivo. Nature 282: 852-855.

Teillet, M. -A., P. Cochard, and N. M. Le Douarin (1978) Relative roles of the mesenchymal tissues and of the complex neural tube-notochord on the expression of adrenergic metabolism in neural crest cells. Zoon 6: 115-122.

Teitelman, G., T. H. Joh, D. Park, M. Brodsky, M. New, and D. J. Reis (1982) Expression of the adrenergic phenotype in cultured fetal adrenal medullary cells: Role of intrinsic and extrinsic factors. Dev. Biol 89: 450-459.

Tischler, A. S., R. L. Perlman, G. M. Morse, and B. E. Sheard (1983) Glucocorticoids increase catecholamine synthesis and storage in PC 12 pheochromocytoma cell cultures. J. Neurochem. 40: 364-370.

Turnell, R. W., N. Kaiser, R. J. Milholland, and F. Rosen (1974) Glucocorticoid receptors in rat thymocytes. Interactions with the antiglucocorticoid cortexolone and mechanism of its action. J. Biol. Chem. 249: 1133-1138.

Williams, L. R., D. Sandquist, A. C. Black, and T. H. Williams (1981) Glucocorticoids increase tyrosine hydroxylase activity in cultured murine neuroblastoma. J. Neurochem. 36: 2057-2062.

Ziller, C., E. Dupin, P. Brazeau, D. Paulin, and N. M. Le Douarin (1983) Early segregation of a neuronal precursor cell line in the neural crest as revealed by culture in a chemically defined medium. Cell 32: 627-638. 